\title{
1 True UV color vision in a butterfly with two UV opsins
}

2

3 Susan D. Finkbeiner ${ }^{1,2^{*}}$ and Adriana D. Briscoe ${ }^{1^{*}}$

4

$5{ }^{1}$ Department of Ecology and Evolutionary Biology, University of California, Irvine, 6 CA 92697, USA

7

$8 \quad{ }^{2}$ Department of Biological Sciences, California State University, Long Beach, CA, 90840, 9 USA

10

$11 *$ Authors for correspondence: abriscoe@uci.edu and susan.finkbeiner@csulb.edu

12

13

14 Running Title: UV color vision in butterflies

15

16 Keywords: Visual system, wavelength discrimination, ultraviolet, insect vision, behavior

17

18 Data Archival: DRYAD (doi: XXXXX)

19

20

21

22 


\section{ABSTRACT}

27 1. True color vision in animals is achieved when wavelength discrimination occurs based on chromatic content of the stimuli, regardless of intensity. In order to successfully discriminate between multiple wavelengths, animals must use at least two photoreceptor types with different spectral sensitivity peaks.

2. Heliconius butterflies have duplicate UV opsin genes, which encode two kinds of photoreceptors with peak sensitivities in the ultraviolet and violet, respectively. In H. erato, the ultraviolet photoreceptor is only expressed in females.

34 3. Evidence from intracellular recordings suggests female $H$. erato may be able to discriminate between UV wavelengths, however, this has yet to be tested experimentally. isabella, to discriminate between two ultraviolet wavelengths, 380 and $390 \mathrm{~nm}$, as well as two blue wavelengths, 400 and $436 \mathrm{~nm}$, after being trained to associate each stimulus with a food reward. Wavelength stimuli were presented in varying

4. Using an arena with a controlled light setting, we tested the ability of H. erato, intensities to rule out brightness as a cue. in the UV range; the other butterflies had an intensity-dependent preference for UV stimuli. Across species, both sexes showed color vision in the blue-range.

6. Models of $H$. erato color vision suggest that females have an advantage over males in discriminating the inner UV-yellow corolla of Psiguria pollen flowers from the surrounding outer orange petals, while previous models (McCulloch et 
al. 2017) suggested that $H$. erato males have an advantage over females in discriminating Heliconius 3-hyroxykynurenine (3-OHK) yellow wing coloration from non-3-OHK yellow wing coloration found in mimics. discrimination in Heliconius females in the context of foraging, lending support to the hypothesis (Briscoe et al. 2010) that the duplicated UV opsin genes function together in UV color vision. Taken together, the sexually dimorphic visual system of $H$. erato appears to have been shaped by both sexual selection and sex-specific

INTRODUCTION natural selection.

62 spectral composition of the stimuli, independent of intensity (Kelber and Pfaff 1999).

63 Animals that have true color vision must use at least two types of photoreceptor, with

64 different spectral sensitivities, to successfully discriminate between wavelengths where

65 their sensitivity curves overlap.

66 Insects use color vision for multiple tasks including foraging (Spaethe et al. 2001,

67 Muth et al. 2015), host plant detection (Scherer and Kolb 1987), and conspecific

68 recognition (Kemp and Rutowski 2011). Most insects have at least one ultraviolet, one

69 blue, and one green photoreceptor, many insects lack red receptors (Briscoe and Chittka

70 2001), and some have lost their blue receptors (Sharkey et al. 2017). Numerous 
71 butterflies, however, have visual systems with more than three photoreceptor classes (van

72 der Kooi et al. 2021).

73 While butterflies typically have only one kind of UV opsin (Briscoe et al. 2003,

74 Koshitaka et al. 2008), and variable numbers of blue and green opsins, Heliconius have

75 duplicated UV opsins (Briscoe et al. 2010). The two UV opsin-encoded photoreceptors

76 have peak sensitivities or $\lambda \max$ values at 355 and $390 \mathrm{~nm}$ as measured by intracellular

77 recordings (McCulloch et al. $2016 a$ ). Although the gene encoding UVRh2, which

78 together with the chromophore produces a violet receptor, is present throughout the

79 genus, the UVRh2 protein, is only expressed at detectable levels in the eye in certain

80 Heliconius clades (specifically the sara and erato clades); it is also sex-specific. In $H$.

81 erato, adult females express both UVRh1 and UVRh2 opsins but males only express the

82 violet receptor with sensitivity at $390 \mathrm{~nm}$ (McCulloch et al. 2017).

83 Heliconius butterflies also have a genus-specific wing pigment, 3-hydroxy-DL-

84 kynurenine (3-OHK), found in the yellow scales of the wings (Brown 1967). Together,

85 the pigment and the wing ultrastructure reflect UV light in the 300-400 $\mathrm{nm}$ range and

86 have a step-like reflectance starting about $440 \mathrm{~nm}$. This wing pigment has evolved in

87 Heliconius along with their duplicated UV opsins (Briscoe et al. 2010), and close

88 relatives to this genus lack both the opsin duplication and the 3-OHK wing pigment

89 (Yuan et al. 2010). It has been proposed that the second UV opsin might allow for better

90 discrimination of yellow-winged Heliconius conspecifics from yellow-winged non-

91 Heliconius mimics (Bybee et al. 2012), perhaps because these butterflies' yellows differ

92 with respect to UV wavelengths; recent experiments lend some support to this hypothesis

93 (Finkbeiner et al. 2017, Dell'Aglio et al. 2018) but more behavioral experiments 
94 examining the functional significance of the duplicate UV opsins are needed.

95 In Heliconius or passion-vine butterflies, adults have large heads relative to body

96 mass (compared to other butterflies) with notable investment in the visual neuropile

97 (Jiggins 2017), implying selective pressures for increased visual function. Heliconius

98 vision has been investigated using a variety of broad and narrow-band stimuli (Crane

99 1955, colored paper flowers; Swihart 1967, narrow band interference filters; Swihart

100 1972, narrow-spectrum color fibers; Zaccardi et al. 2006, narrow band interference

101 filters). Available evidence demonstrates that Heliconius have true color vision in the

102 long wavelength range (Zaccardi et al. 2006) but so far investigations in the short

103 wavelength range have been limited.

104 Here we test whether Heliconius erato are capable of discriminating between

105 narrow band wavelengths within in the UV range in the context of foraging. We use male

106 and female $H$. erato butterflies, and as controls, male and female H. melpomene and

107 Eueides isabella butterflies. Both H. melpomene and E. isabella lack a second UV opsin

108 protein expressed in the eye but for different reasons: protein expression of UVRh2 was

109 lost in H. melpomene (McCulloch et al. 2017), and E. isabella - a closely-related

110 outgroup — never evolved a second UV opsin (Yuan et al. 2010). By confirming UV

111 color discrimination in $H$. erato butterflies, and ruling it out in $H$. melpomene and $E$.

112 isabella, we demonstrate the functional significance of their UV opsin duplication.

113

\section{METHODS}

115 Animals

116 Butterflies were purchased as pupae from the Costa Rica Entomological Supply 
117 (La Guácima, Costa Rica). The pupae were kept in a humidified chamber until they

118 eclosed, then they were sexed and marked with a unique number. The butterflies were fed

119 using a 10\% honey solution with one bee pollen granule dissolved per $2 \mathrm{ml}$ of solution.

120 Butterflies were only allowed to feed on the positive stimulus during the training and

121 testing. A total of 362 butterflies were used in the study, of which 200 were successfully

122 trained and used in complete trials: $80 \mathrm{H}$. erato (40 females, 40 males); $80 \mathrm{H}$. melpomene

123 (40 females, 40 males); and 40 E. isabella (20 females, 20 males).

\section{Behavioral experiments and apparatus}

126 The experiments and training took place indoors in a mesh enclosure constructed

127 from PVC pipes, measuring $1 \mathrm{~m} \times 75 \mathrm{~cm} \times 75 \mathrm{~cm}$, and the room temperature was $24^{\circ} \mathrm{C}$.

128 The top of the enclosure was lined with 8 fluorescent tubes (Philips TLD 96518 W;

129 Eindhoven, The Netherlands). Our apparatus for training and experiments was based on a

130 design described in Zaccardi et al. (2006) and previously used to test color vision in the

131 monarch butterfly (Blackiston et al. 2011; see also Swihart and Swihart 1970, Weiss and

132 Papaj 2003, Takeuchi et al. 2006, Rodrigues et al. 2010, Kinoshita and Arikawa 2014,

133 and Drewniak et al. 2020 for other apparatus' used in butterfly visual learning). It

134 consists of two $3.0 \mathrm{~cm}$ diameter stimuli presented side-by-side, separated by $6 \mathrm{~cm}$ on two

135 black platforms set on a larger black plate, measuring a total of $20 \mathrm{~cm} \times 10 \mathrm{~cm}$ (see

136 Figure 2 and Supporting Video 1). The apparatus was positioned vertically at the far end

137 of the enclosure. Two wavelength stimuli were presented to the butterflies at a time.

138 Light was emitted from two KL2500 Schott cold light sources (Mainx, Germany) into

139 light guides held stable with a light guide holder. The light from each guide passed 
140 through a diffusor, a $10 \mathrm{~nm}$ narrow band-pass filter (Edmund Optics; Barrington, NJ,

141 USA), and then through a transparent Plexiglass feeder disk (see Figure 3 in Zaccardi et

142 al. 2006 for a diagram). For our experiments we used four narrow band-pass filters in

143 paired choice tests: $380 \mathrm{~nm}$ versus $390 \mathrm{~nm}$, and $400 \mathrm{~nm}$ versus $436 \mathrm{~nm}$. We use 380 and

$144390 \mathrm{~nm}$ as the UV stimuli because the sensitivity curves of the two UV photoreceptors

145 overlap in this range (McCulloch et al. 2016a) (Figure 1). If the butterflies have UV color

146 discrimination using the UV and the violet photoreceptors together then we would expect

147 that they would be able to discriminate between these two wavelengths. We also chose

$148400 \mathrm{~nm}$ and $436 \mathrm{~nm}$ as a control for color vision in all three species using the UV and

149 blue photoreceptors. The light intensities for each wavelength were adjusted so that

150 between these four wavelengths of light, the intensities for the experiments ranged from

$1519.56 \times 10^{15}$ to $1.71 \times 10^{17} ;$ quanta $\mathrm{s}^{-1} \operatorname{steradian}^{-1} \mathrm{~cm}^{-2}$.

153 Butterfly training

154 Butterflies were trained and fed for the first time within 15 hours of eclosion.

155 Before training, they were allowed to acclimate to the experimental cage up to one

156 minute, and only one butterfly was trained at a time. A droplet of food was placed in a

157 small trough attached to the front of the feeder disk for the rewarded stimulus $(+)$. The

158 unrewarded stimulus (-) feeder trough remained empty. Each butterfly was trained by

159 having its wings held together with forceps, and then slowly moved from the rear of the

160 enclosure toward the apparatus to simulate a flying motion. The butterfly was then slowly

161 waved in front of both the rewarded and unrewarded stimuli, and finally held in front of

162 the rewarded stimulus where its proboscis was uncoiled with an insect pin until it came 
163 into contact with the food solution. At this point the butterfly would begin to drink. After

164 the proboscis was manually uncoiled 2-3 times, the butterfly was able to uncoil the

165 proboscis on its own in response to the stimulus. The procedure of carrying the butterfly

166 with forceps from the rear of the cage to the light sources to feed was repeated 5 times

167 per training session, with two training sessions per day separated by approximately 6

168 hours. Each time the butterfly fed from the rewarded stimulus, it was allowed to drink for

16910 seconds, except for the very last training segment of the day where it was allowed to

170 drink for several minutes. During training and between training sessions, the placement

171 of the rewarded and unrewarded stimuli was randomly switched so that the butterfly did

172 not learn to associate the left or right light with a food source. The apparatus was also

173 cleaned thoroughly after each training session to minimize the association of chemical

174 cues to the stimulus. After about 4-5 days of training, butterflies were capable of

175 independently flying toward the apparatus when released from the rear of the cage and

176 making a choice to fly to one of the two light stimuli (Supporting Video 1). At this point,

177 the trained butterflies were starved for 20-24 hours then their choice trials began.

179 Experimental trials

180 A separate cohort of butterflies was trained with each wavelength pair because the

181 butterflies did not survive long enough to be trained multiple times. Both sexes of each

182 species were first trained to $390 \mathrm{~nm}(+)$, and then tested for UV discrimination ability

183 between $390 \mathrm{~nm}(+)$ and $380 \mathrm{~nm}(-)$ (ten per sex for H. erato and H. melpomene and five

184 per sex for E. isabella). The same number of individuals was trained to $380 \mathrm{~nm}(+)$ and

185 given the choice between the two UV stimuli. Two new cohorts of butterflies were used 
186 for reciprocal training to $400 \mathrm{~nm}$ and to $436 \mathrm{~nm}$. Three different approximate ratios of the

187 physical intensities, or absolute brightnesses, of the $+/-$ (rewarded/unrewarded) stimuli

188 were used: $0.067,1.0$, and 15.0 (or 1:15, 1:1, and 15:1). The calculated ratios are 0.062 ,

$1891.0,16.213$ for 380 vs. $390 \mathrm{~nm}$; and $0.0635,1.0,15.741$ for 400 vs. $436 \mathrm{~nm}$. These

190 intensity ratios are described throughout the rest of this study as $1: 15,1: 1$, and $15: 1$, i.e.

191 the rewarded stimulus (+) at 15 times less bright than the unrewarded stimulus (-), equal

192 intensities for both stimuli, and the rewarded stimulus $(+)$ at 15 times brighter than

193 unrewarded stimulus (-). Butterflies first completed trials at an intensity combination of

$194 \quad 1: 1$ (15 choices each). Following this test they were given random choices between

195 intensities of 1:15 or 15:1 (rewarded:unrewarded) until they had completed 15 choices

196 with each intensity combination.

197 The number of correct versus incorrect choices each butterfly made at different

198 intensity combinations was modeled as dependent upon wavelength using general linear

199 models in R statistical software (R Development Core Team 2010). We compared the

200 ability of each category of butterfly to discriminate between the wavelength combinations

201 at the different intensities. We also examined how discrimination abilities differed

202 between all three butterfly species used in the study.

203

204 Reflectance spectrometry

205 Live tissue was collected by accessing the butterfly and plant collection of Dr. Lawrence

206 Gilbert at the Brackenridge Field Laboratory at the University of Texas, Austin on July

207 20, 2010. Reflectance spectra of Heliconius erato petiverana eggs, Passiflora biflora egg

208 mimics, Psychotria tomentosa yellow infloresences, red bracts, and green leaves and 
209 Psiguria warcewiczii yellow and orange inflorescences and green leaves were measured

210 by placing a probe holder (Ocean Optics RPH-1) over the specimen such that the axis of

211 the illuminating and detecting fiber (Ocean Optics R400-7-UV/VIS) was at an elevation

212 of 45 degrees to the plane of the tissue surface. Illumination was by a DH-2000

213 deuterium-halogen lamp, and reflectance spectra were measured with an Ocean Optics

214 USB2000 spectrometer. Data were processed in MATLAB. Four to nine biological

215 replicates per taxon were measured for each tissue type.

\section{Discriminability Modeling}

218 To examine whether male or female $H$. erato eyes perform differently when viewing

219 ecologically relevant objects, we constructed visual models. Models of color vision take

220 into account how receptor signals contribute to chromatic (e.g., color opponent)

221 mechanisms (Kelber et al. 2003). For H. erato males, we calculated discriminabilities for

222 a trichromatic system consisting of UV2, blue and green receptors. For $H$. erato females,

223 we calculated discriminabilities for a tetrachromatic system consisting of UV1, UV2,

224 blue and green receptors. We excluded the red receptor from our calculations for both

225 sexes because we do not have count data for this receptor class. Equations from Kelber et

226 al. (2003) and Vorobyev \& Osorio (1998) were used to model discriminabilities. This

227 model incorporates a von Kries's transformation, that is, normalization by the

228 illumination spectrum, which models the way in which low-level mechanisms such as

229 photoreceptor adaptation give color constancy (Kelber et al. 2003). Endler's daylight

230 illumination spectrum (Endler 1993) was used in the model. H. erato photoreceptor

231 spectral sensitivity curves with $\lambda_{\max }$ values $=355 \mathrm{~nm}$ (UV1)(female only), $390 \mathrm{~nm}$ (UV2), 
$232470 \mathrm{~nm}(\mathrm{~B})$, and $555 \mathrm{~nm}$ (L) from (McCulloch et al. 2016a) were used. Parameters for

233 the butterfly visual models were as follows: Weber fraction=0.05 (Koshitaka et al. 2008)

234 and relative abundances of photoreceptors, $\mathrm{V}=0.13, \mathrm{~B}=0.2, \mathrm{~L}=1$ (male) or $\mathrm{UV}=0.09$,

$235 \mathrm{~V}=0.07, \mathrm{~B}=0.17, \mathrm{~L}=1$ (females) (McCulloch et al. 2016a).

237 RESULTS

238 UV discrimination

239 At the intensity of 1:1 for 390 and $380 \mathrm{~nm}$ light, female $H$. erato chose the

240 rewarded light stimulus, $390 \mathrm{~nm}(+)$, significantly more than the unrewarded stimulus,

$241380 \mathrm{~nm}(-)(\mathrm{z}$-value $=6.791, \mathrm{p}<0.0001$, Figure 3A). This indicates the ability of female

242 H. erato to distinguish between the two UV wavelengths. The females continued to

243 choose the correct, rewarded color stimulus under varying light intensity combinations.

244 At an intensity ratio of 1:15 (rewarded : unrewarded), females significantly chose $390 \mathrm{~nm}$

$245(+)$ over $380 \mathrm{~nm}(-)(\mathrm{z}$-value $=5.19, \mathrm{p}<0.0001)$; and at an intensity of 15:1 (rewarded :

246 unrewarded), females also chose $390 \mathrm{~nm}(+)$ over $380 \mathrm{~nm}(-)(\mathrm{z}$-value $=7.35, \mathrm{p}<$

247 0.0001). There was no difference between female preference for the correct stimulus with

248 a 1:1 and 1:15 light ratio $(z-v a l u e=-0.794, p=0.427)$, or with a 1:1 and 15:1 light ratio

$249 \quad(z-v a l u e=0.319, p=0.749)$, showing that females chose the correct light stimulus $(390$

$250 \mathrm{~nm}$ ) equally across all tested light intensity combinations.

251 With respect to male behavior, at the intensity of $1: 1$ for $390(+)$ and $380 \mathrm{~nm}(-)$,

252 male H. erato chose both the rewarded and unrewarded light stimuli equally (z-value = -

$2530.49, \mathrm{p}=0.624$, Figure 3B). This suggests they cannot distinguish between the two UV

254 wavelengths. However, the males significantly preferred the correct, rewarded stimulus 
$255(390 \mathrm{~nm})(+)$ when it was presented 15x brighter than the unrewarded stimulus (ratio 15:1

256 for rewarded : unrewarded; $\mathrm{z}$-value $=6.421, \mathrm{p}<0.0001$ ); and they significantly preferred

257 the incorrect, unrewarded stimulus, $380 \mathrm{~nm}(-)$, at the intensity of 1:15 (rewarded :

258 unrewarded; $z$-value $=-6.671, \mathrm{p}<0.0001)$. These results imply that males prefer the

259 brighter stimulus regardless of light wavelength, and further support their inability to

260 discriminate between 390 and $380 \mathrm{~nm}$. Comparing male and female performance,

261 females significantly prefer the correct stimulus $(390 \mathrm{~nm})(+)$ more than males when 390

262 vs. $380 \mathrm{~nm}$ are at intensities of 1:1 (z-value $=-3.427, \mathrm{p}=0.0006)$, and at intensities of

$2631: 15(\mathrm{z}-\mathrm{value}=-6.126, \mathrm{p}<0.0001)$, respectively. However, males and females equally

264 chose the correct stimulus, $390 \mathrm{~nm}(+)$, when the rewarded:unrewarded intensity ratio

265 was at 15:1 (z-value $=-0.514, \mathrm{p}=0.607$, Figure $3 \mathrm{~A}, \mathrm{~B})$.

266 With H. melpomene and E. isabella, at the intensity of 1:1 for 390 and $380 \mathrm{~nm}$,

267 both sexes had similar wavelength discrimination behavior to male $H$. erato in that they

268 chose both the rewarded $(390 \mathrm{~nm})(+)$ and unrewarded $(380 \mathrm{~nm})(-)$ light stimuli equally

269 (z-value $=0.923, \mathrm{p}=0.356$ for $H$. melpomene, Figure $3 \mathrm{C}, \mathrm{D}$; $\mathrm{z}$-value $=0.327, \mathrm{p}=0.744$

270 for E. isabella, Figure 3 E,F). They were able to significantly choose the correct stimulus

$271(390 \mathrm{~nm})(+)$ only when it was $15 x$ brighter than the unrewarded stimulus $(\mathrm{z}$-value $=$ -

$27210.79, \mathrm{p}<0.0001$ for H. melpomene; $\mathrm{z}$-value $=6.791, \mathrm{p}<0.0001$ for E. isabella), and

273 they chose the unrewarded stimulus $(380 \mathrm{~nm})(-)$ significantly more when it was $15 \mathrm{x}$

274 brighter than the rewarded, correct stimulus (z-value $=10.460, \mathrm{p}<0.0001$ for $H$.

275 melpomene; $\mathrm{z}$-value $=-6.293, \mathrm{p}<0.0001$ for E. isabella). No behavioral differences

276 between sexes of either species were detected with statistical analyses (all $p>0.05$ ), 
277 indicating that discrimination ability was consistent between both males and females of 278 H. melpomene and E. isabella.

279 For the reciprocally rewarded tests, female H. erato butterflies were again

280 consistent in discriminating between the rewarded $(380 \mathrm{~nm})(+)$ and unrewarded $(390$

$281 \mathrm{~nm})(-)$ stimuli when intensities were the same (z-value $=-6.671, \mathrm{p}<0.0001$, Supporting

282 Figure 1A), when the rewarded stimulus was $15 x$ brighter $(\mathrm{z}$-value $=-7.793, \mathrm{p}<0.0001)$,

283 and when the rewarded stimulus was $15 \mathrm{x}$ less bright $(\mathrm{z}$-value $=-5.194, \mathrm{p}<0.0001)$.

284 Male $H$. erato butterflies were incapable of discriminating between the different

285 wavelengths when presented at equal intensities ( $\mathrm{z}$-value $=-0.327, \mathrm{p}=0.744$, Supporting

286 Figure 1B), and chose the incorrect stimulus when it was $15 x$ brighter than the correct,

287 rewarded stimulus $(\mathrm{z}$-value $=6.162, \mathrm{p}<0.0001)$. Males did, however, choose the correct

288 stimulus when presented at an intensity ratio of $15 \mathrm{x}$ brighter than the unrewarded

289 stimulus $(\mathrm{z}$-value $=-5.194, \mathrm{p}<0.0001)$. Females correctly chose the rewarded stimulus

$290(380 \mathrm{~nm})(+)$ significantly more than males at intensity ratios of $1: 1(\mathrm{z}$-value $=-2.976, \mathrm{p}=$

$2910.00292)$ and 1:15 $(\mathrm{z}$-value $=-5.793, \mathrm{p}<0.0001)$, but at a ratio of 15:1 male and female

292 H. erato chose the correct wavelength at similar rates (z-value $=-1.424, \mathrm{p}=0.154$,

293 Supporting Figure 1 A,B).

294 Like male H. erato, H. melpomene and E. isabella could not distinguish between

295 the two UV wavelengths presented at a 1:1 intensity ratio (z-value $=0.462, \mathrm{p}=0.644$ for

296 H. melpomene, Supporting Figure $1 \mathrm{C}, \mathrm{D} ; \mathrm{z}-\mathrm{value}=0.327, \mathrm{p}=0.744$ for E. isabella,

297 Supporting Figure 1 E,F). They significantly preferred the rewarded stimulus only when

$29815 \mathrm{x}$ brighter $(\mathrm{z}$-value $=-11.12, \mathrm{p}<0.0001$ for $H$. melpomene; $\mathrm{z}$-value $=-7.024, \mathrm{p}<$

2990.0001 for E. isabella), and preferred the unrewarded stimulus also only when $15 \mathrm{x}$ 
300 brighter $(\mathrm{z}$-value $=7.793, \mathrm{p}<0.0001$ for $H$. melpomene; $z$-value $=7.346, \mathrm{p}<0.0001$ for

301 E. isabella). Male and female discrimination behavior did not differ between $H$.

302 melpomene or E. isabella $(\mathrm{p}>0.05)$. In summary, female H. erato always discriminated

303 between 380 and $390 \mathrm{~nm}$ light, consistently preferring the correct, rewarded stimulus,

304 whereas male $H$. erato, male and female $H$. melpomene, and male and female E. isabella

305 struggled with UV discrimination and only chose the correct stimulus when it was at a

306 brighter intensity than the incorrect, unrewarded stimulus.

Short wavelength discrimination

To investigate color vision in the blue range, we repeated the series of

310 discrimination tests using $400 \mathrm{~nm}$ and $436 \mathrm{~nm}$ which would allow short wavelength

311 discrimination using a UV or violet photoreceptor and a blue photoreceptor. As expected,

312 when trained to $400 \mathrm{~nm}(+)$, female $H$. erato chose the correct stimulus when offered

313 both light wavelengths at equal intensities ( $\mathrm{z}$-value $=-7.93, \mathrm{p}<0.0001$, Figure $4 \mathrm{~A}$ ), at an

314 intensity of 1:15 for rewarded:unrewarded (z-value $=-7.54, \mathrm{p}<0.0001)$, and at an

315 intensity of 15:1 of rewarded:unrewarded light (z-value $=-8.099, \mathrm{p}<0.0001)$. Male $H$.

316 erato, male and female $H$. melpomene, and E. isabella behavior paralleled female

317 discrimination behavior between the two blue wavelengths, with male $H$. erato choosing

318 the correct wavelength at intensity combinations of $1: 1$ (z-value $=-7.93, \mathrm{p}<0.0001$,

319 Figure 4B), 1:15 (z-value $=-7.54, \mathrm{p}<0.0001)$, and 15:1 (z-value $=-7.987, \mathrm{p}<0.0001)$

320 and H. melpomene and E. isabella males and females also choosing the correct, rewarded

321 wavelengths at intensity ratios of $1: 1$ (z-value $=-11.46, \mathrm{p}<0.0001$ for $H$. melpomene,

322 Figure 4 C,D; z-value = -7.63, p $<0.0001$ for E. is abella, Figure 4 E,F), 1:15 (z-value = - 
$32311.07, \mathrm{p}<0.0001$ for H. melpomene; $\mathrm{z}-\mathrm{value}=-6.671, \mathrm{p}<0.0001$ for E. isabella), and

$32415: 1$ (z-value $=-11.47, \mathrm{p}<0.0001$ for $H$. melpomene; $\mathrm{z}$-value $=-7.445, \mathrm{p}<0.0001$ for $E$.

325 isabella).

326 When trained to $436 \mathrm{~nm}(+)$, all butterflies continued to show a significant

327 preference for the correct wavelength stimulus regardless of intensity. Female and male

328 H. erato preferred the rewarded stimulus at equal intensities (z-value $=7.930, p<0.0001$

329 for females, Supporting Figure 2A; z-value $=7.714, \mathrm{p}<0.0001$ for males, Supporting

330 Figure $2 B$ ), at an intensity combination of 1:15 (z-value $=7.242, p<0.0001$ for females;

$331 \mathrm{z}$-value $=6.909, \mathrm{p}<0.0001$ for males $)$, and at 15:1 (z-value $=7.987, \mathrm{p}<0.0001$ for

332 females; $z$-value $=7.865, \mathrm{p}<0.0001$ for males). H. melpomene and E. isabella followed

333 the same trend and significantly preferred the correct wavelength $(436 \mathrm{~nm})(+)$ at an

334 intensity combination of $1: 1(\mathrm{z}$-value $=-10.85, \mathrm{p}<0.0001$ for $H$. melpomene Supporting

335 Figure 2 C,D; z-value $=7.793, \mathrm{p}<0.0001$ for E. isabella, Supporting Figure 2 E,F), 1:15

336 (z-value $=-9.853, \mathrm{p}<0.0001$ for H. melpomene; $\mathrm{z}$-value $=6.293, \mathrm{p}<0.0001$ for $E$.

337 isabella), and 15:1 (z-value $=-11.07, \mathrm{p}<0.0001$ for $H$. melpomene; $\mathrm{z}=7.930, \mathrm{p}<0.0001$

338 for E. isabella). There was no difference between $H$. erato male and female behavior,

339 between $H$. melpomene male and female behavior, or between H. erato, H. melpomene,

340 and E. isabella behavior (all $\mathrm{p}>0.05$ ) for selecting the correct light wavelength when

341 trained to either $400 \mathrm{~nm}$ or $436 \mathrm{~nm}$. All butterflies expressed the same ability to

342 discriminate between $400 \mathrm{~nm}$ and $436 \mathrm{~nm}$ across all three intensity combinations.

344 DISCUSSION 
346 range, between $380 \mathrm{~nm}$ and $390 \mathrm{~nm}$, and that this is a female-limited behavior. Our

347 results provide behavioral evidence that these butterflies can discriminate between more

348 than one UV color using an ultraviolet and a violet photoreceptor, which suggests that the

$349 U V R h 1$ (ultraviolet) and UVRh2 (violet) opsin genes in H. erato function in the context of

350 UV color discrimination. We also show that H. erato, H. melpomene, and E. isabella

351 have color vision in the blue range between $400 \mathrm{~nm}$ and $436 \mathrm{~nm}$, using both an UV and

352 blue photoreceptor.

353 True UV color discrimination in H. erato is possible because of the evolution of a

354 violet-sensitive photoreceptor, UVRh2, which has been present since the genus originated

355 (Briscoe et al. 2010). As noted above, some clades (e.g., H. melpomene) do not express

356 the UVRh2 protein at detectable levels in the adult compound eye despite expressing the

357 UVRh2 mRNA, due to ongoing pseudogenization (McCulloch et al. 2017). Opsin

358 duplication events are not uncommon in butterflies (Sison-Mangus et al. 2006, Lienard et

359 al. 2020). For example, the lycaenid butterfly Polyommatus icarus uses its duplicated

360 blue opsin to see green, perhaps for discrimination of oviposition sites (Sison-Mangus et

361 al. 2008). The pierid butterfly Pieris rapae has both a duplicated blue opsin and

362 spectrally tuned filtering pigments: photoreceptor modifications that may be crucial for

363 mate recognition by males (Arikawa et al. 2005; Wakakuwa et al. 2010). Yet another

364 study has found that while both sexes of the wood tiger moth, Arcia plantaginis can

365 distinguish between white and yellow male morphs (and females prefer to mate with

366 white males), variation in female orange and red coloration is indiscriminable by both 
367 sexes, suggesting the moths' visual system has evolved to facilitate female choice (Henze

368 et al. 2018).

369 In Heliconius erato females, duplicate UV opsin genes encoding a UV and a

370 violet receptor allow for UV color discrimination. The diversity of duplicated UV opsin

371 presence or absence and spatial expression across the genus Heliconius is nonetheless

372 thought-provoking. Male H. erato butterflies evidently use their duplicated UVRh2

373 (violet), blue, and long wavelength opsins in the context of mate choice discrimination of

374 3-OHK versus non-3-OHK yellow wing colors (Finkbeiner et al. 2017), an advantage

375 predicted by modeling the discrimination abilities of $H$. erato males in comparison with a

376 hypothetical male $H$. erato visual system in which UVRh1 takes the place of UVRh2

377 (Table 1) (McCulloch et al. 2017). Moreover, the loss of UVRh2 protein expression in $H$.

378 melpomene (which use their ancestral UVRh1 opsin and not UVRh2) may contribute to

379 increased attempts to mate with other species due to a reduction in visual ability to

380 recognize conspecifics (Bybee et al. 2012, Dell'Aglio et al. 2019). Heliconius are part of

381 a large mimicry complex that includes both unpalatable within-genus Müllerian mimics

382 (which display 3-OHK yellow wing pigments) and palatable Batesian mimics such as

383 Eueides isabella (which display unknown yellow wing pigments) (Srygley and Chai

384 1990; Bybee et al. 2012). Consequently, Heliconius erato (but not H. melpomene)

385 butterflies benefit from having the violet receptor, UVRh2, which facilitates

386 discrimination of yellow pigments of mimics from those of conspecifics.

387 Early visual modeling of the Heliconius visual system suggested an additional

388 benefit to Heliconius ' displaying 3-OHK yellow pigments on the wing: with a second UV

389 opsin in their eyes, more colors can be discriminated among Heliconius yellows than can 
390 be discriminated among the yellows of outgroup taxa (Briscoe et al. 2010). More recent

391 work suggests Heliconius species may indeed be more conspicuous to conspecifics in

392 their preferred habitats and light environment (Dell'Aglio et al. 2018, Dell'Aglio et al.

393 2019).

394 Both H. erato and H. melpomene may interact together by forming communal

395 roosts in the same home range, which would provide added anti-predatory benefits

396 through a similar visual signal (Finkbeiner et al. 2012). Heliconius co-mimics have been

397 observed foraging together (pers. obs.) and roosting together (although uncommon;

398 Mallet 1986, Finkbeiner 2014), and this could represent one instance where identifying a

399 Heliconius individual (whether or not a co-species) would be beneficial. Aside from

400 visual signals, Heliconius frequently use pheromone cues for conspecific recognition,

401 especially for short-range signaling, for example during courtship behavior (Estrada and

402 Jiggins 2008, Darragh et al. 2017, van Schooten et al. 2020).

403 It is possible that the adaptive function of UV color discrimination in female $H$.

404 erato butterflies extends beyond intra- and interspecific communication to include host

405 plant or pollen plant recognition. Within Heliconius, different species are specialists on

406 Passiflora host plants for oviposition, and some of these Passiflora species contain

407 extrafloral nectaries that resemble yellow Heliconius eggs (Williams and Gilbert 1981).

408 Heliconius are known to avoid ovipositing on host plants that already have eggs because

409 larvae have cannibalistic tendencies (Brown 1982, De Nardin and Araújo 2011), and

410 fresh, new shoots that are the most edible for larvae can be of limited quantity (Gilbert

411 1982). While it is possible that the egg mimic structures differ spectrally from actual eggs

412 in their UV reflectance, thus potentially allowing the additional UV opsin to provide 
413 discrimination between natural and mimic eggs, our preliminary investigation of the

414 reflectance spectra of $H$. erato petiverana eggs and Passiflora biflora egg mimics,

415 indicates that there is little to no UV reflectance for either the eggs or the egg mimics

416 (Figure 5, top). Moreover, visual models indicate that both male and female H. erato

417 visual systems are both able to discriminate H. erato eggs from Passiflora biflora egg

418 mimics (Table 1), and P. biflora egg mimics from P. biflora leaves but not H. erato eggs

419 from P. biflora leaves (Figure 5, bottom).

420 There is also the possibility that the leaves of caterpillar host plants, or even the

421 petals of adult pollen flowers (such as Psychotria and Psiguria) have unique spectral

422 properties in the UV range that would make a second UV/violet opsin beneficial.

423 Intriguingly, we found evidence of a UV component to the reflectance spectra of the

424 yellow inflorescences of Psychotria tomentosa, a plant from which Heliconius

425 prolifically collect pollen (Figure 6, top). Both male and female H. erato visual systems

426 appear adept, however, at discriminating between the yellow inflorescence from the red

427 bracts of Psychotria tomentosa and at discriminating the red bracts from the green

428 Psychotria leaf (Table 1, Figure 6, bottom). We also found that the yellow inner part of

429 the Psiguria warcewiczii inflorescence has an even brighter UV component (Figure 7,

430 top). Notably, the female $H$. erato visual system seems to have a bit of an advantage over

431 the male $H$. erato visual system in discriminating the inner yellow from the outer orange

432 petals of Psiguria warcewiczii flowers (Table 1, Figure 7 bottom). This difference is

433 intriguing in light of evidence that female Heliconius charitonia (which have similar

434 visual systems to $H$. erato)(McCulloch et al. 2017) collect significantly more pollen than

435 do male $H$. charitonia because of their higher protein requirements for egg production 
436 (Boggs 1981; Boggs et al. 1981; Cardoso 2001; Estrada and Jiggins 2002; Mendoza-

437 Cuenca and Macías-Ordóñez 2005); H. charitonia also display a sexual dimorphism in

438 the flowers they collect pollen from with females preferring Hamelia patens pollen and

439 males preferring Lantana camara flowers in one study locality (Mendoza-Cuenca and

440 Macías-Ordóñez 2005).

441 An additional area ripe for exploration although not considered in the present

442 study is in the investigation of ultraviolet polarized light cues in the context of host plant

443 recognition. At least two studies of butterfly oviposition behavior have found that Papilio

444 and Pieris butterflies respond to visible wavelength polarized light cues (Kelber et al.

445 2001; Blake et al. 2020), and previous work on Heliconius cydno finds they are able to

446 use polarized light as a mating cue (Sweeney et al. 2003). Extending future investigations

447 of Heliconius erato behavior to include UV polarized cues in the context of oviposition

448 and mate choice seems likely to yield further insights into selective forces driving the

449 evolution of this visual system's sexual dimorphism.

450 Other animals that have photoreceptor spectral sensitivity in the UV range likely

451 have true UV color discrimination, although to rule out brightness discrimination further

452 experimentation is needed. Hummingbird hawkmoths (Macroglossum stellatarum) can

453 discriminate between $365 \mathrm{~nm}$ and $380 \mathrm{~nm}$, but it is unclear whether they are able to do so

454 by means of true color vision or an achromatic cue (Kelber and Henique 1999). A

455 different study showed that these moths are indeed able to discriminate between long

456 wavelength stimuli under a range of intensities (Telles et al. 2016). In the case of the

457 mantis shrimp and similar stomatopods, whose compound eyes possess the largest

458 number of photoreceptor types known in any animal (including four UV-sensitive 
459 photoreceptors, Marshall and Oberwinkler 1999), there is little indication that their

460 photoreceptors function with respect to true color vision at all (Thoen et al. 2014).

461 However, our study provides clear evidence that despite differences in light intensity, $H$.

462 erato female butterflies have the ability to discriminate between two UV wavelengths,

463 lending support to the hypothesis that the new UV opsin gene in Heliconius functions in

464 the context of UV color discrimination, and is one of the first to show that an animal can

465 see multiple UV wavelengths using true color vision. In conclusion, our current and prior

466 findings strongly suggest that both sexual selection and sex-specific natural selection

467 have shaped the sexually-dimorphic visual system of Heliconius erato.

\section{ACKNOWLEDGEMENTS}

471 We are grateful to Lawrence Gilbert for permission to measure reflectance spectra from

472 host plants and flowers housed in the Brackenridge Field Laboratory; Robert Reed,

473 Kailen Mooney, and Nancy Burley for advice and aid in project design; Paola Vargas and

474 the Costa Rica Entomological Supply for providing live butterflies for experiments; Kyle

475 McCulloch and Aide Macias-Muñoz for manuscript feedback and assistance with live

476 butterfly care; and our funding sources: the U.S. Department of Education GAANN

477 Fellowship, and the National Science Foundation (NSF) Graduate Research Fellowship

478 under award no. DGE-0808392 to S.D.F. and NSF grant no. IOS-1257627 and IOS-

4791656260 to A.D.B. 
483 Arikawa, K., Wakakuwa, M., Qiu, X., Kurasawa, M., \& Stavenga, D. G. (2005). Sexual

484 dimorphism of short-wavelength photoreceptors in the Small White butterfly,

485 Pieris rapae crucivora. Journal of Neuroscience, 25, 5935-5942.

486 https://doi.org/10.1523/JNEUROSCI.1364-05.2005

487

488 Blackiston, D., Briscoe, A. D., \& Weiss, M. R. (2011). Color vision and learning in the

489 monarch butterfly, Danaus plexippus (Nymphalidae). Journal of Experimental Biology,

$490 \quad 214$, 509-520. doi: 10.1242/jeb.048728

491

492 Blake, A. J., Hahn, G. S., Grey, H., Kwok, S. A., McIntosh, D., \& Gries, G. (2020).

493 Polarized light sensitivity in Pieris rapae is dependent on both color and intensity.

494 Journal of Experimental Biology, 223, jeb220350. doi: 10.1242/jeb.220350

496 Boggs, C. L. (1981). Nutritional and life-history determinants of resource

497 allocation in holometabolous insects. The American Naturalist, 117, 692-709.

498

499 Boggs, C. L., Smiley, J. T. \& Gilbert, L. E. (1981). Patterns of pollen exploitation by

500 Heliconius butterflies. Oecologia, 48, 284-289.

501

502 
503 Boggs, C. L., Smiley, J. T., \& Gilbert, L. E. (1981). Patterns of pollen exploitation by

504 Heliconius butterflies. Oecologia, 48, 284-289. https://doi.org/10.1007/BF00347978

505

506 Briscoe, A. D., Bernard, G. D., Szeto, A. S., Nagy, L. M., \& White, R. H. (2003). Not all

507 butterfly eyes are created equal: Rhodopsin absorption spectra, molecular identification

508 and localization of ultraviolet-, blue-, and green-sensitive rhodopsin-encoding mRNAs in

509 the retina of Vanessa cardui. Journal of Comparative Neurology, 458, 334-349.

510 https://doi.org/10.1002/cne. 10582

511

512 Briscoe, A. D., Bybee, S. M., Bernard, G. D., Yuan, F., Sison-Mangus, M. P., Reed, R.

513 D., Warren, A. D., Llorente-Bousquets, J., \& Chiao, C.-C. (2010). Positive selection of a

514 duplicated UV-sensitive visual pigment coincides with wing pigment evolution in

515 Heliconius butterflies. Proceedings of the National Academy of Sciences, U.S.A., 107,

516 3628-3633. https://doi.org/10.1073/pnas.0910085107

517

518 Briscoe, A. D., \& Chittka, L. (2001). The evolution of color vision in insects. Annual

519 Review of Entomology, 46, 471-510. doi:10.1146/annurev.ento.46.1.471

521 Brown, K. S. Jr. (1981). The biology of Heliconius and related genera. Annual Review of

522 Entomology, 26, 427-456. https://doi.org/10.1146/annurev.en.26.010181.002235 
524 Brown, K. S. (1967). Chemotaxonomy and chemomimicry: The case of 3-

525 hydroxykynurenine. Systematic Zoology, 16, 213-216. https://doi.org/10.2307/2412068

527 Bybee, S. M., Yuan, F., Ramstetter, M. D., Llorente-Bousquets, J., Reed, R. D., Osorio,

528 D., \& Briscoe, A. D. (2012). UV photoreceptors and UV-yellow wing pigments in

529 Heliconius butterflies allow a color signal to serve both mimicry and intraspecific

530 communication. The American Naturalist, 179, 38-51. doi: 10.1086/663192

532 Cardoso, M. Z. (2001). Patterns of pollen collection and flower visitation by Heliconius

533 butterflies in southeastern Mexico. Journal of Tropical Ecology, 17, 763-768.

535 Crane, J. (1955). Imaginal behaviour of a Trinidad butterfly, Heliconius erato hydara

536 Hewitson, with special reference to the social use of color. Zoologica, 40, 167-196.

538 Darragh, K., Vanjari, S., Mann, F., Gonzalez-Rojas, M. F., Morrison, C. R., Salazar, C., 539 et al. (2017). Male sex pheromone components in Heliconius butterflies released by the

540 androconia affect female choice. Peer J, 5, e3953.

542 Dell’Aglio, D. D., Troscianko, J., McMillan, W. O., Stevens, M., \& Jiggins, C. D. (2018).

543 The appearance of mimetic Heliconius butterflies to predators and conspecifics.

544 Evolution, 72, 2156-2166. 
546 Dell’Aglio, D. D., Troscianko, J., Stevens, M., McMillan, W. O., \& Jiggins, C. D. (2019).

547 The conspicuousness of the toxic Heliconius butterflies across time and habitat. BioRxiv.

548 doi: https://doi.org/10.1101/662155

550 De Nardin, J., \& Araújo, A. (2011). Kin recognition in immatures of Heliconius erato

551 phyllis (Lepidoptera; Nymphalidae). Journal of Ethology, 23, 499-503.

552

553 Drewniak, M. E., Briscoe, A. D., Cocucci, A. A., Beccacece, H. M., Zapata, A. I., \&

554 Moré, M. (2020). From the butterfly’s point of view: learned colour association

555 determines differential pollination of two co-occurring mock verbains by Agraulis vanilla

556 (Nymphalidae). Biological Journal of the Linnaen Society, 130, 715-725. doi:

557 10.1093/biolinnean/blaa066

558

559 Endler, J.A. (1993). The color of light in forests and its implications. Ecological

560 Monographs, 63, 1-27.

561

562 Estrada, C., \& Jiggins, C. D. (2002). Patterns of pollen feeding and habitat preference

563 among Heliconius species. Ecologial Entomology, 27, 448-456.

564

565 Estrada, C., \& Jiggins, C. D. (2008). Interspecific sexual attraction because of

566 convergence in warning colouration: is there a conflict between natural and sexual

567 selection in mimetic species? Journal of Evolutionary Biology, 21, 749-760. 
569 Finkbeiner, S. D. (2014). Communal roosting in Heliconius butterflies (Nymphalidae):

570 Roost recruitment, establishment, fidelity, and resource use trends based on age and sex.

571 Journal of the Lepidopterists' Society, 68, 10-16.

572

573 Finkbeiner, S. D., Briscoe, A. D., \& Reed, R. D. (2012). The benefit of being a social

574 butterfly: communal roosting deters predation. Proceedings of the Royal Society of

575 London B., 279, 2769-2776. doi:10.1098/rspb.2012.0203

576

577 Finkbeiner, S. D., Fishman, D. A., Osorio, D., \& Briscoe, A. D. (2017). Ultraviolet and

578 yellow reflectance but not fluorescence is important for visual discrimination of

579 conspecifics by Heliconius erato. Journal of Experimental Biology, 220, 1267-1276.

580 doi: $10.1242 /$ jeb. 153593

581

582 Gilbert, L. E. (1972). Pollen feeding and reproductive biology of Heliconius butterflies.

583 Proceedings of the National Academy of Sciences U.S.A., 69, 1403-1407.

584

585 ------. (1982). The coevolution of a butterfly and a vine. Scientific American, 247, 110-

586121.

587

588 Henze, M. J., Lind, O., Mappes, J. M., Rojas, B., \& Kelber, A. (2018). An aposematic

589 colour-polymorphic moth seen through the eyes of conspecifics and predators -

590 sensitivity and colour discrimination in a tiger moth. Functional Ecology, 32, 1797-1809.

591 doi:10.1111/1365-2435.13100 
593 Jiggins, C. D. (2017). The Ecology and Evolution of Heliconius Butterflies. Oxford

594 University Press, Oxford, U.K.

595

596 Kelber, A., \& Hénique, U. (1999). Trichromatic colour vision in the hummingbird

597 hawkmoth, Macroglossum stellatarum L. Journal of Comparative Physiology A. 184, $598 \quad 535-541$.

600 Kelber, A., \& Pfaff, M. (1999). True colour vision in the orchard butterfly, Papilio

601 aegeus. Naturwissenschaften, 86, 221-224.

602

603 Kelber, A., Thunell, C., \& Arikawa, K. (2001). Polarisation-dependent colour vision in

604 Papilio butterflies. Journal of Experimental Biology, 204, 2469-2480.

605

606 Kelber A, Vorobyev M, Osorio D. (2003). Animal colour vision: behavioural tests and 607 physiological concepts. Biological Reviews, 78, 81-118.

608

609 Kemp, D. J., \& Rutowski, R. L. (2011). The role of coloration in mate choice and sexual 610 interactions in butterflies. Advances in the Study of Behavior, 43, 55-92.

611

612 Kinoshita, M., \& Arikawa, K. (2014). Color and polarization vision in foraging Papilio.

613 Journal of Comparative Physiology A., 200, 513-526. doi:10.1007/s00359-014-0903-5 
615 Koshitaka, H., Kinoshita, M., Vorobyev, M., \& Arikawa, K. (2008). Tetrachromacy in a

616 butterfly that has eight varieties of spectral receptors. Proceedings of the Royal Society of

617 London B., 275, 947-954.

619 Lienard, M. A., Bernard, G. D., Allen, A. A, Lassance, J-M., Song, S., Rabideau

620 Childers, R. A., Yu, N., Ye, D., Stephenson, A., Valencia-Montoya, W. A., Salzman, S.,

621 Whitaker, M. R. L., Calonje, M., \& Pierce, N. E. (2020). The evolution of red colour

622 vision is linked to coordinated rhodopsin tuning in lycaenid butterflies. bioRxiv

623 doi:https://doi.org/10.1101/2020.04.06.027102

624

625 Mallet, J. (1986). Gregarious roosting and home range in Heliconius butterflies. National

626 Geographic Research, 2, 198-215.

628 Marshall, J., \& Oberwinkler, J. (1999). Ultraviolet vision: The colourful world of the

629 mantis shrimp. Nature, 401, 873-874.

631 McCulloch, K. J., Osorio, D. C., \& Briscoe, A. D. (2016a). Sexual dimorphism in the

632 compound eye of Heliconius erato: a nymphalid butterfly with at least five spectral

633 classes of photoreceptor. Journal of Experimental Biology, 219, 2366-2387.

634 doi: $10.1242 /$ jeb. 136523 
636 McCulloch, K., Osorio, D., \& Briscoe, A. D. (2016b). Determination of photoreceptor

637 cell spectral sensitivity in an insect model from in vivo intracellular recordings. Journal

638 of Visualized Experiments, 108, e53829. doi:10.3791/53829

640 McCulloch, K. J., Yuan, F., Zhen, Y., Aardema, M. L., Smith, G., Llorente-Bousquets, J.,

641 Andolfatto, P., \& Briscoe, A. D. (2017). Sexual dimorphism and retinal mosaic

642 diversification following the evolution of a violet receptor in butterflies. Molecular

643 Biology and Evolution, 34, 2271-2284. doi:10.1093/molbev/msx163

645 Mendoza-Cuenca, L., \& Macías-Ordóñez, R. (2005). Foraging polymorphism in

646 Heliconius charitonia (Lepidoptera: Nymphalidae): morphological constraints and

647 behavioural compensation. Journal of Tropical Ecology, 21, 407-415.

648 doi:10.1017/S0266467405002385

650 Muth, F., Papaj, D. R. , \& Leonard, A. S. (2015). Colour learning when foraging for

651 nectar and pollen: bees learn two colours at once. Biology Letters, 11, 20150628.

652 https://doi.org/10.1098/rsbl.2015.0628

653

654 Rodrigues, D., Goodner, B. W., \& Weiss, M. R. (2010). Reversal learning and risk-averse

655 foraging behavior in the monarch butterfly, Danaus plexippus (Lepidoptera:

656 Nymphalidae). Ethology, 116, 270-280.

657

658 R Development Core Team. (2010). R: A language and environment for statistical 
659 computing. R Foundation for Statistical Computing, Vienna, Austria.

660

661 Scherer, C., \& Kolb, G. (1987). Behavioral experiments on the visual processing of color

662 stimuli in Pieris brassicae L. (Lepidoptera). Journal of Comparative Physiology A, 160,

$663 \quad 645-656$.

664

665 Sharkey, C. R., Fujumoto, M. S., Lord, N. P., Shin, S., McKenna, D. D., Suvorov, A.,

666 Martin, G. J., \& Bybee, S. M. (2017). Overcoming the loss of blue sensitivity through

667 opsin duplication in the largest animal group, beetles. Scientific Reports, 7, 8.

668

669 Sison-Mangus, M. P., Bernard, G. D., Lampel, J., \& Briscoe, A. D. (2006). Beauty in the

670 eye of the beholder: The two blue opsins of lycaenid butterflies and the opsin gene-driven

671 evolution of sexually dimorphic eyes. Journal of Experimental Biology, 209, 3079-3090.

672 doi:10.1242/jeb.02

673

674 Sison-Mangus, M. P., Briscoe, A. D., Zaccardi, G., Knüttel, H., \& Kelber, A. (2008). The

675 lycaenid butterfly Polyommatus icarus uses a duplicated blue opsin to see green. Journal

676 of Experimental Biology, 211, 361-369. doi: 10.1242/jeb.012617

677

678 Spaethe, J., Tautz, J., \& Chittka, L. (2001). Visual constraints in foraging bumblebees:

679 flower size and color affect search time and flight behavior. Proceedings of the National

680 Academy of Sciences U.S.A., 98, 3898-3903. https://doi.org/10.1073/pnas.071053098 
682 Srygley, R. B., \& Chai, P. (1990). Flight morphology of Neotropical butterflies:

683 palatability and distribution of mass to the thorax and abdomen. Oecologia, 84, 491-499.

684

685 Sweeney, A., Jiggins, C. D., \& Johnsen, S. (2003). Polarized light as a butterfly mating

686 signal. Nature, 423, 31-32. https://doi.org/10.1038/423031a

687

688 Swihart, S. L. (1967). Neural adaptations in the visual pathway of certain heliconiine

689 butterflies and related forms to variations in wing coloration. Zoologica, New York, 52, 1-

69014.

691

692 ------. (1972). The neural basis of color-vision in the butterfly, Heliconius erato. Journal

693 of Insect Physiology, 18, 1015-1025.

694

695 Swihart, C. A., \& Swihart, S. L. (1970). Colour selection and learned feeding preferences

696 in the butterfly, Heliconius charitonius Linn. Animal Behavior, 18, 60-64.

697

698 Takeuchi, Y., Arikawa, K., \& Kinoshita, M. (2006). Color discrimination at the spatial

699 resolution limit in a swallowtail butterfly, Papilio xuthus. Journal of Experimental

700 Biology, 209, 2873-2879. doi:10.1242/jeb.02311

701

702 Telles, F. J., Kelber, A., \& Rodriguez-Gironés, M. A. (2016). Wavelength discrimination

703 in the hummingbird hawkmoth Macroglossum stellatarum. Journal of Experimental

704 Biology, 219, 553-560. 
706 Thoen, H. H., How, M. J., Chiou, T.-H., \& Marshall, J. (2014). A different form of color

707 vision in mantis shrimp. Science, 343, 411-413.

708

709 van der Kooi, C. J., Stavenga, D. G., Arikawa, K., Belusic, G., \& Kelber, A. In press.

710 Evolution of insect colour vision - from spectral sensitivity to visual ecology. Annual

711 Review of Entomology doi: 10.1146/annurev-ento-061720-071644.

712

713 van Schooten, B., Meléndez-Rosa, J., Van Belleghem, S. M., Jiggins, C. D., Tan, J. D.,

714 McMillan, W. O., \& Papa, R. (2020). Divergence of chemosensing during the early

715 stages of speciation. Proceedings of the National Academy of Sciences U.S.A., 117,

716 16438-16447 doi.org/10.1073/pnas.1921318117

717

718 Vorobyev, M., \&Osorio, D. (1998). Receptor noise as a determinant of colour thresholds.

719 Proceedings of the Royal Society of London B, 265, 351-358.

721 Wakakuwa, M., Terakita, A., Koyanagi, M., Stavenga, D. G., Shichida, Y., \& Arikawa,

722 K. (2010). Evolution and mechanism of spectral tuning of blue-absorbing visual pigments

723 in butterflies. PLoS One, 5, e15015.

724

725 Weiss, M. D., \& Papaj, D. R. (2003). Colour learning in two behavioural contexts: how 726 much can a butterfly keep in mind? Animal Behavior, 65, 425-434. 
728 Williams, K. S., \& Gilbert, L. E. (1981). Insects as selective agents on plant vegetative

729 morphology - egg mimicry reduces egg-laying by butterflies. Science, 212, 467-469.

730

731 Yuan, F., Bernard, G. D., Le, J., \& Briscoe, A. D. (2010). Contrasting modes of evolution

732 of the visual pigments in Heliconius butterflies. Molecular Biology and Evolution, 27,

733 2392-2405. doi: 10.1093/molbev/msq12.

734

735 Zaccardi, G., Kelber, A., Sison-Mangus, M. P., \& Briscoe, A. D. (2006). Color

736 discrimination in the red range with only one long-wavelength sensitive opsin. Journal of

737 Experimental Biology, 209, 1944-1955. doi: 10.1242/jeb.02207 
740 TABLE 1. Percentage of Heliconius egg, egg mimic, pollen flower and wing colors with

741 chromatic just noticeable difference (JND) values $>1$ for male and female $H$. erato eyes.

\begin{tabular}{lccc}
\hline & N & Male (\%) & Female (\%) \\
\hline $\begin{array}{l}\text { H. erato eggs. vs. Passiflora biflora } \\
\text { egg mimics }\end{array}$ & 16 & $100 \%$ & $100 \%$ \\
$\begin{array}{l}\text { Psychotria tomentosa yellow flowers } \\
\text { vs. red bracts }\end{array}$ & 16 & $100 \%$ & $100 \%$ \\
$\begin{array}{l}\text { Psychotria tomentosa red bracts vs. } \\
\text { green leaves }\end{array}$ & 16 & $100 \%$ & $100 \%$ \\
$\begin{array}{l}\text { Psiguria warcewiczii inner corolla } \\
\text { yellow vs. outer orange petals }\end{array}$ & 25 & $80 \%$ & $96 \%$ \\
$\begin{array}{l}\text { Psiguria warcewiczii } \\
\text { outer orange petals vs. green leaves }\end{array}$ & 25 & $100 \%$ & $100 \%$ \\
$\begin{array}{l}\text { Heliconius } \text { vs. Eueides wing dorsal } \\
\text { yellow }\end{array}$ & 144 & $78.5 \%$ & $45.1 \%$ \\
$\begin{array}{l}\text { Heliconius } \text { vs. Eueides } \text { wing ventral } \\
\text { yellow }\end{array}$ & 117 & $87.2 \%$ & $84.6 \%$ \\
\hline
\end{tabular}

742

743 NOTE. - Two systems are modeled: male and female $H$. erato eyes under high light,

744 sunny illumination. The male eye includes UV1, B and L opsins, the female eye includes

745 UV1, UV2, B and L opsins. The red receptor found in both sexes is not included in the

746 visual modeling because their relative abundance is unknown.

747 †From Table 1 of McCulloch et al. (2017).

749 FIGURE LEGENDS

750 Figure 1: Normalized spectral sensitivities of the photoreceptors in adult (A) female and

751 (B) male H. erato based on recorded intracellular spectral sensitivity maxima (McCulloch

752 et al. $2016 a, b$ ). The UV photoreceptor (dark purple), encoded by UVRh1, has a peak

753 sensitivity at $355 \mathrm{~nm}$, the violet photoreceptor (light purple), encoded by UVRh2, has a

754 peak sensitivity at $390 \mathrm{~nm}$, the blue photoreceptor (blue), encoded by the blue opsin has a 
755 peak sensitivity of $470 \mathrm{~nm}$ and the green photoreceptor (green), encoded by the LWR

756 opsin, has a peak sensitivity at $555 \mathrm{~nm}$. A fifth known receptor class, with a peak at 600

$757 \mathrm{~nm}$ due to filtering of the green rhodopsin by a red filtering pigment is not shown. Dotted

758 lines represent the wavelength of peak transmission of the narrow bandpass fibers, 380

$759 \mathrm{~nm}, 390 \mathrm{~nm}, 400 \mathrm{~nm}$ and $436 \mathrm{~nm}$, used in discrimination tests. Male H. erato (B), lacking

760 the UV photoreceptor (dark purple) are unable to discriminate between 380 and $390 \mathrm{~nm}$

761 light. H. melpomene and Eueides isabella, for different reasons, do not express the

762 UVRh2 (light purple) opsin protein in their eye.

763

764 Figure 2: Experimental design of behavioral trials and experimental apparatus. (A)

765 Female and male butterflies of three species, Heliconius erato, H. melpomene and E.

766 isabella were reciprocally trained to associate honey water with a rewarded light $(+)$ and

767 tested using an apparatus (B) consisting of a rewarded light and an unrewarded light (-).

768 Butterflies were trained and tested on their ability to discriminate $380 \mathrm{~nm}$ (right) from

$769390 \mathrm{~nm}$ (left) and $400 \mathrm{~nm}$ from 436nm lights (not shown). Shown is a male H. erato

770 butterfly that has just landed on the light source apparatus during a trial.

771

772 Figure 3: Percent correct choices to the rewarded (+) wavelength of $390 \mathrm{~nm}$ by H. erato

773 females (A) and males (B), H. melpomene females (C) and males (D), and E. isabella

774 females (E) and males (F) when given a choice between $390 \mathrm{~nm}(+)$ and $380 \mathrm{~nm}(-)$ light

775 under varying intensities.

776

777 Figure 4: Percent correct choices to the rewarded (+) wavelength of $400 \mathrm{~nm}$ by H. erato

778 females (A) and males (B), H. melpomene females (C) and males (D), and E. isabella 
779 females (E) and males (F) when given a choice between $400 \mathrm{~nm}(+)$ and $436 \mathrm{~nm}(-)$ light

780 under varying intensities.

782 Figure 5: Reflectance spectra (top) and color contrasts (bottom) of H. erato eggs (dark

783 grey line) and egg mimics (orange line) found on the leaves (green line) of H. erato host

784 plant, Passiflora biflora. Shaded areas correspond to 95\% confidence intervals, N=4.

785 Black lines indicate UV1, UV2, blue, and green photoreceptors' normalized spectral

786 sensitivities. Not shown is the red receptor that is the result of filtering the green receptor

787 with a red filtering pigment. Data from McCulloch et al. (2016 a, b). Bottom: Color

788 contrasts between $H$. erato eggs and $P$. biflora leaves $(\mathrm{N}=16)(\mathrm{left})$ and between $P$. biflora

789 egg mimics and $P$. biflora leaves $(\mathrm{N}=16)$ (right) in just noticeable differences (JNDs).

790 Whiskers correspond to upper and lower limits. The absolute threshold is 1 JND;

791 however in butterflies, the receptor noise levels are not well known so this is an

792 approximation. Inset: $P$. biflora photograph with yellow arrow indicating egg mimic by C

793 T Johansson. Source: Wikimedia: CC BY (https://creativecommons.org/licenses/by/3.0).

795 Figure 6: Reflectance spectra (top) and color contrasts (bottom) of Psychotria tomentosa

796 yellow inflorescence (yellow line), red bracts (red line) and green leaves (green line), a

797 plant from which Heliconius butterflies collect pollen. Shaded areas correspond to 95\%

798 confidence intervals, $\mathrm{N}=4-5$. Black lines indicate UV1, UV2, blue, and green

799 photoreceptors' normalized spectral sensitivities. Data from McCulloch et al. (2016 $a, b)$.

800 Bottom: Color contrasts between yellow inflorescence and red bracts $(\mathrm{N}=16)(\mathrm{left})$ and

801 red bracts and green leaves $(\mathrm{N}=16)$ (right) in just noticeable differences (JNDs). Whiskers 
802 correspond to upper and lower limits. The absolute threshold is 1 JND; however in

803 butterflies, the receptor noise levels are not well known so this is an approximation. Inset:

$804 P$. tomentosa photograph with yellow arrow indicating the yellow inflorescence.

805 Surrounding the inflorescence are red bracts.

807 Figure 7: Reflectance spectra (top) and color contrasts (bottom) of Psiguria

808 warcewiczii-yellow flower center (yellow line), outer orange petals (red line), light

809 green corolla (dotted green line) and green leaves (solid green line) — a plant from which

810 adult Heliconius butterflies collect pollen. Shaded areas correspond to $95 \%$ confidence

811 intervals, $\mathrm{N}=5-9$. Black lines indicate UV1, UV2, blue, and green photoreceptors'

812 normalized spectral sensitivities. Data from McCulloch et al. (2016 a,b). Bottom: Color

813 contrasts between yellow flower center and outer orange petals $(\mathrm{N}=25)$ (left) and between

814 outer orange petals and green leaves $(\mathrm{N}=25)$ (right) in just noticeable differences (JNDs).

815 Whiskers correspond to upper and lower limits. The absolute threshold is 1 JND;

816 however in butterflies, the receptor noise levels are not well known so this is an

817 approximation. Inset: P. warcewiczii photograph. Photo credit: Steven Paton,

818 Smithsonian Tropical Research Institute. Reprinted with permission.

820 SUPPORTING INFORMATION

821 Supporting Figure 1: Percent correct choices to the rewarded $(+)$ wavelength of $380 \mathrm{~nm}$

822 by $H$. erato females (A) and males (B), H. melpomene females (C) and males (D), and E.

823 isabella females (E) and males (F) when given a choice between $380 \mathrm{~nm}(+)$ and $390 \mathrm{~nm}$

824 (-) light under varying intensities. 
826 Supporting Figure 2: Percent correct choices to the rewarded $(+)$ wavelength of $436 \mathrm{~nm}$

827 by $H$. erato females (A) and males (B), H. melpomene females (C) and males (D), and E.

828 isabella females (E) and males (F) when given a choice between $436 \mathrm{~nm}(+)$ and $400 \mathrm{~nm}$

829 (-) light under varying intensities.

830

831 Supporting Video 1: A male $H$. erato butterfly is shown flying towards, and landing, on

832 the light source apparatus during a trial. The light wavelengths presented are $390 \mathrm{~nm}$

833 (left) and $380 \mathrm{~nm}$ (right). The male chose $380 \mathrm{~nm}$, the unrewarded stimulus, while it was

834 presented at $15 \mathrm{x}$ brighter than the rewarded light stimulus of $390 \mathrm{~nm}$. 

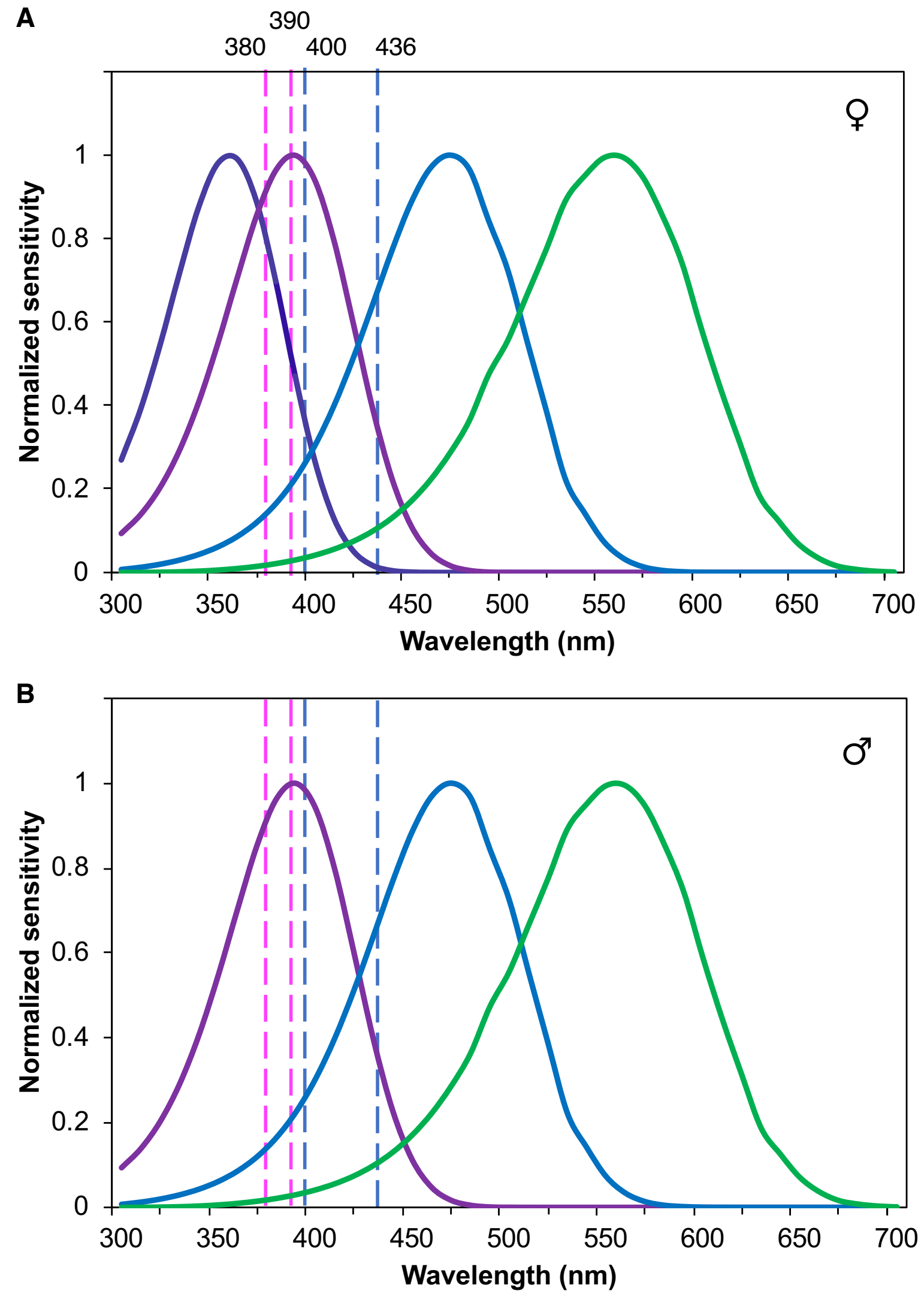

Figure 1 


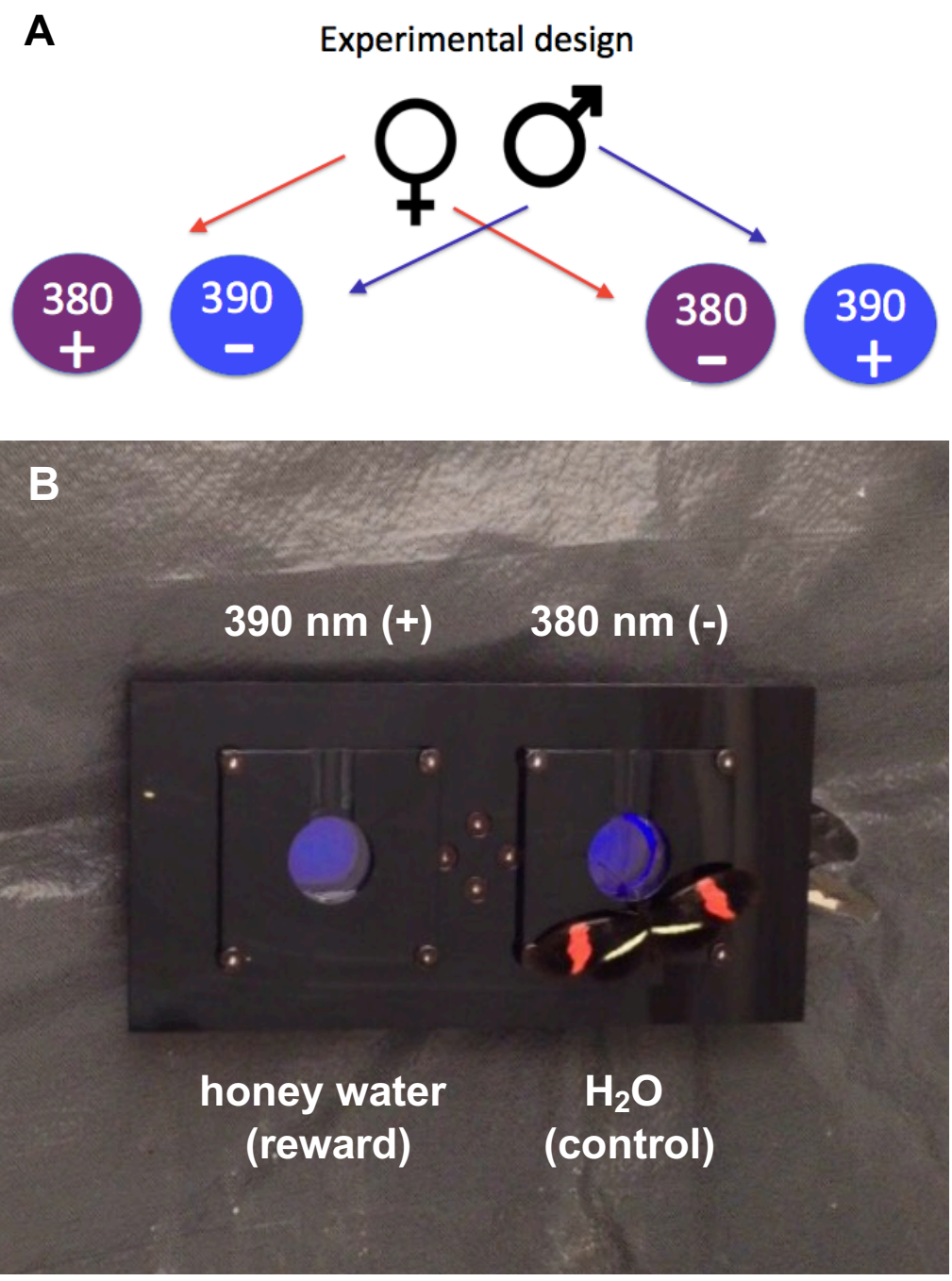

Figure 2 
A

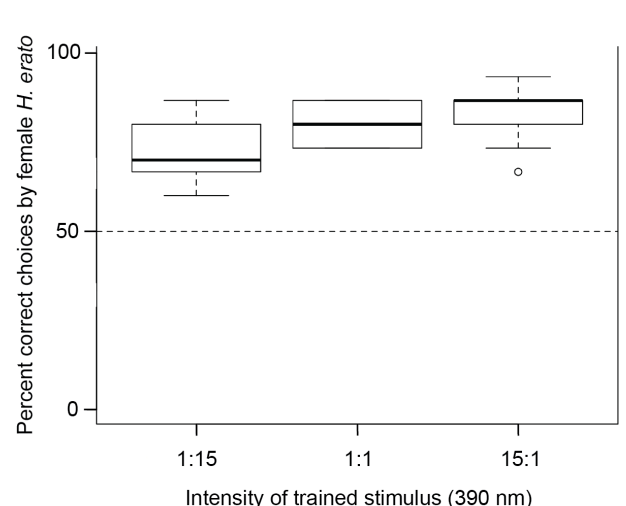

B

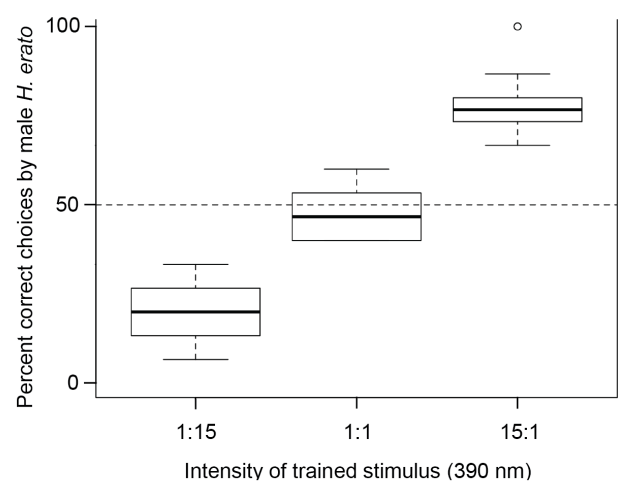

C

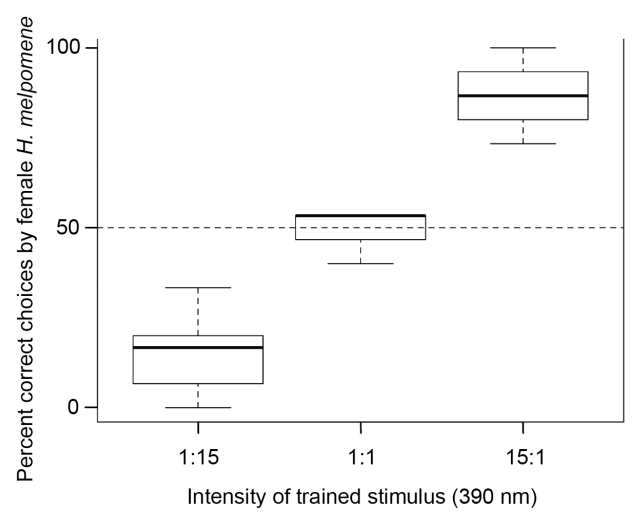

D

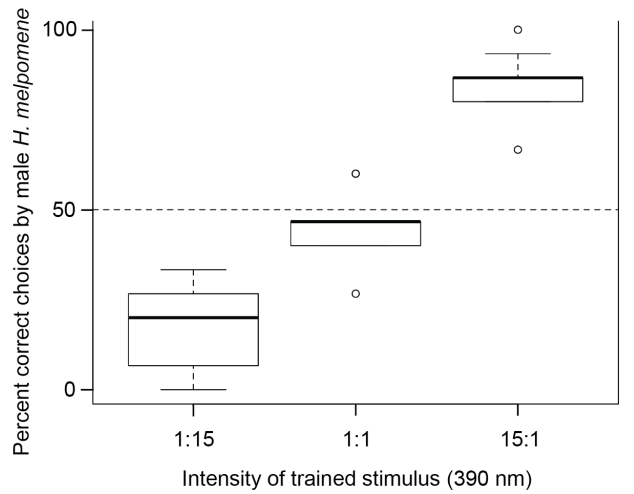

E

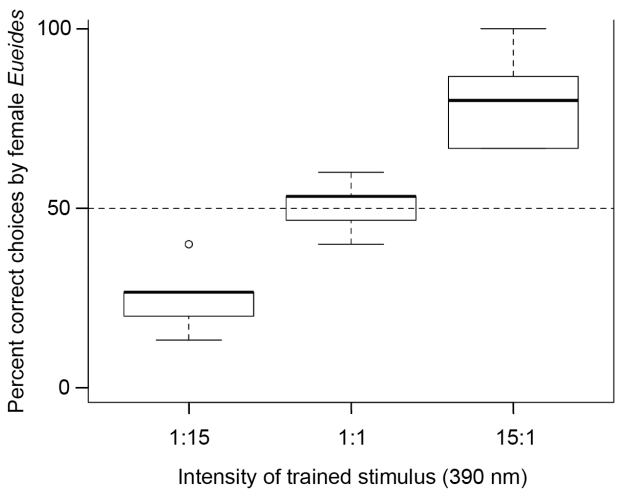

F

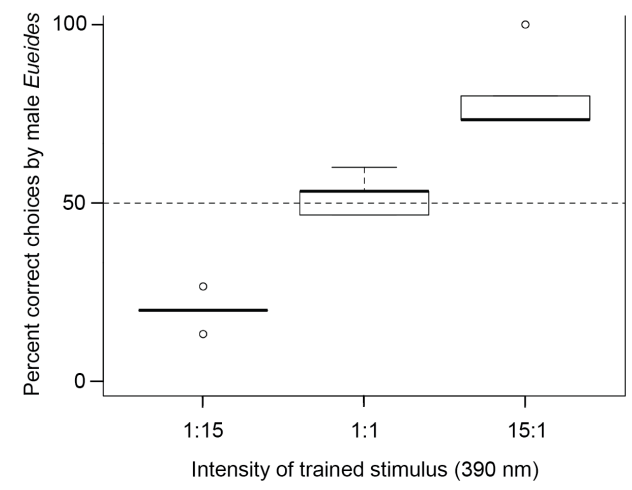

Figure 3 
A

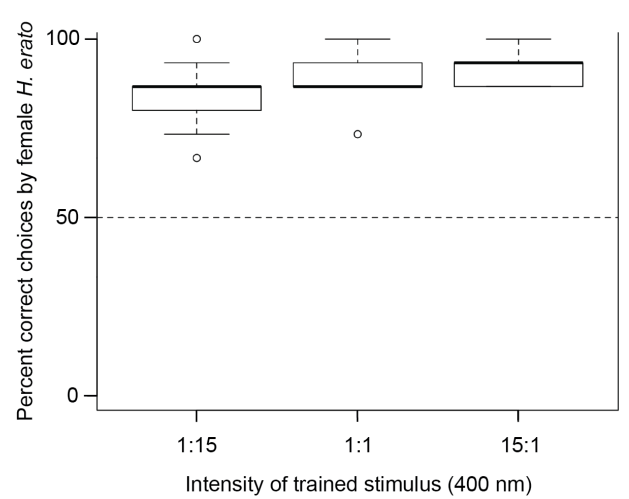

B

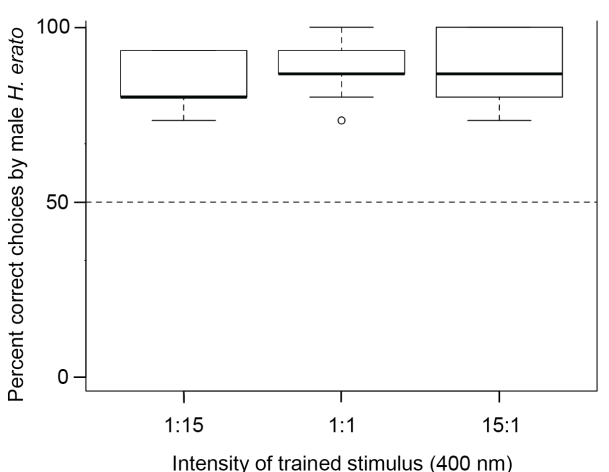

C

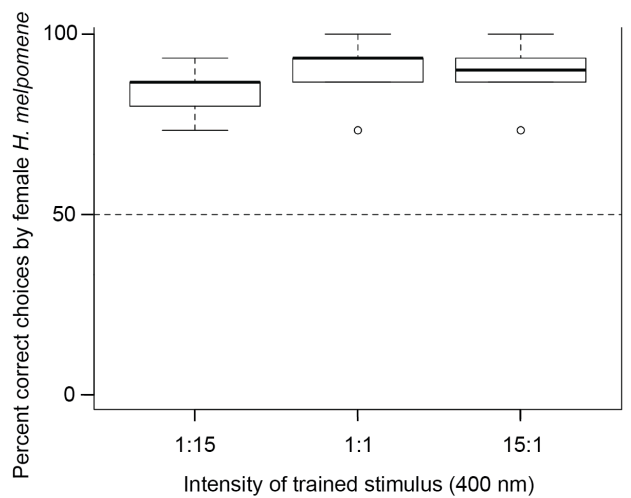

D

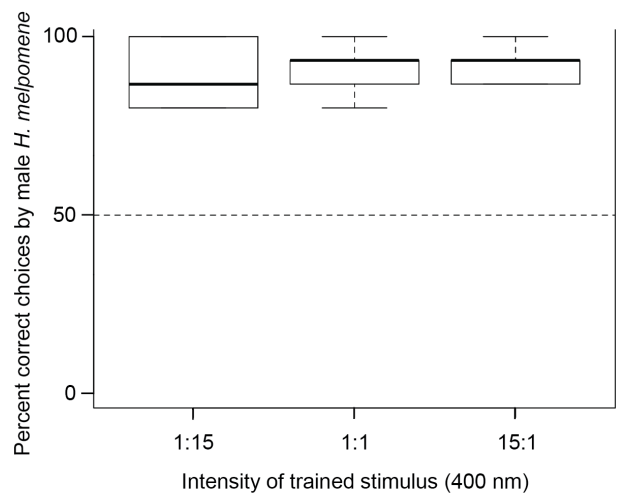

E

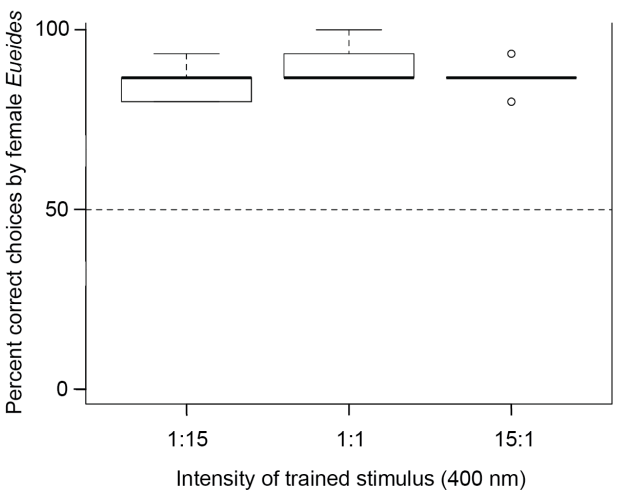

F

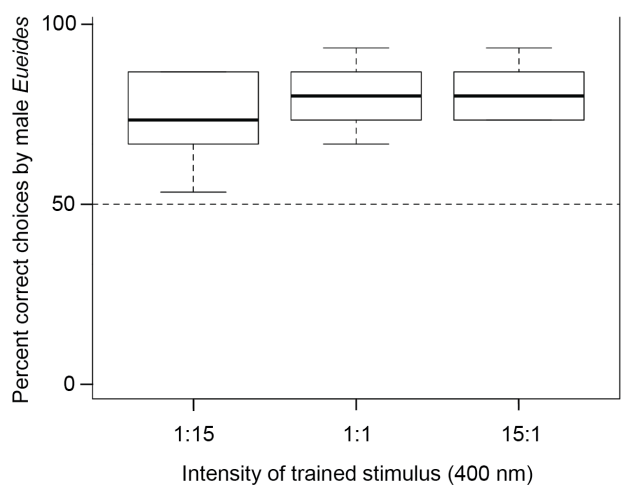

Figure 4 

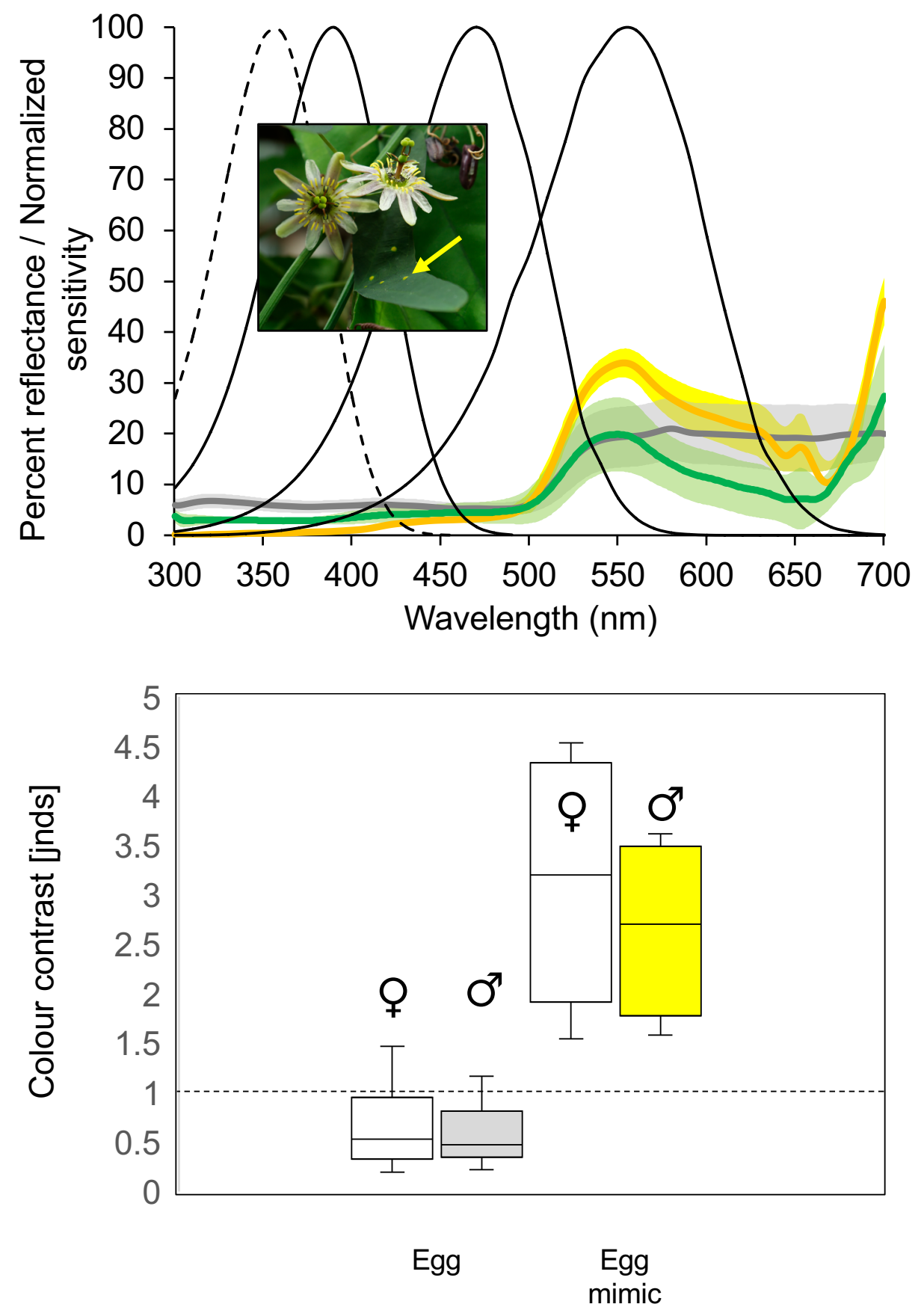

Figure 5 

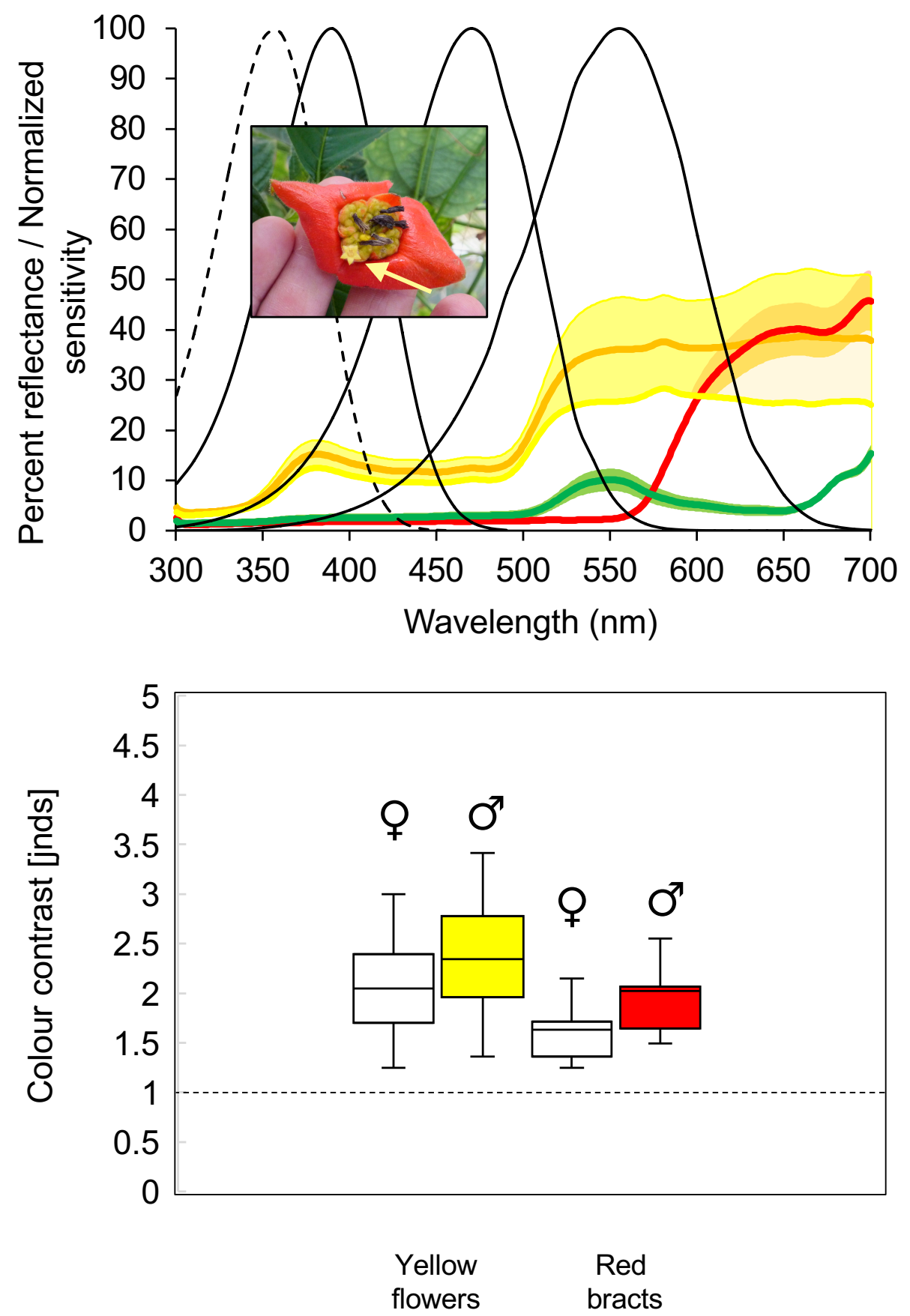

Figure 6 

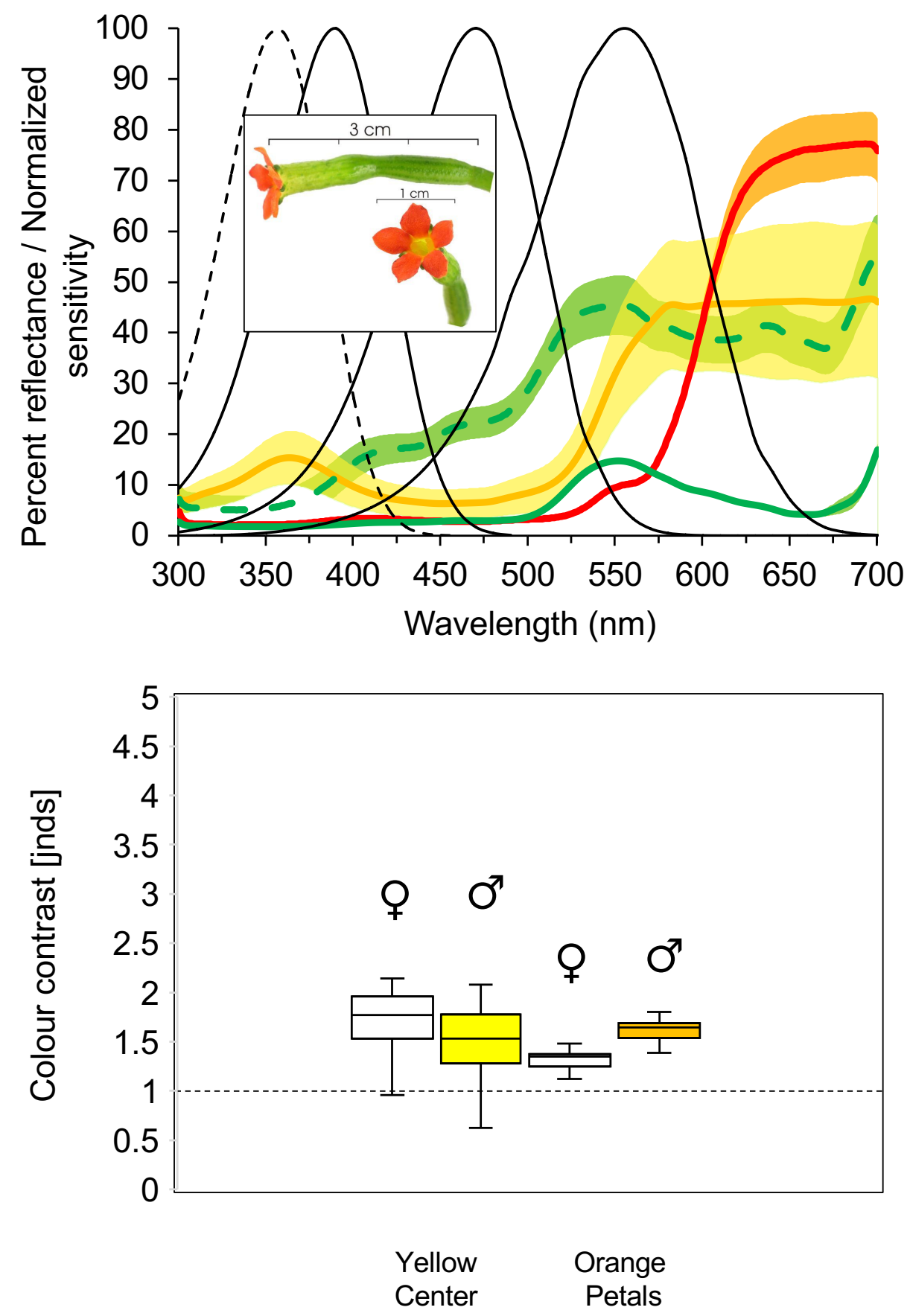

Figure 7 